\title{
A Shift From Competition To Facilitation With Abiotic Stress is Limited For Two Codominant Grass Species
}

Jesse E. Gray ( $\sim$ jesse.gray@colostate.edu )

Colorado State University https://orcid.org/0000-0002-9075-5030

Melinda D. Smith

Colorado State University

\section{Research Article}

Keywords: codominance, coexistence, Andropogon gerardii, Sorghastrum nutans, stress gradient hypothesis, drought

Posted Date: December 3rd, 2021

DOl: https://doi.org/10.21203/rs.3.rs-1120324/v1

License: (c) (i) This work is licensed under a Creative Commons Attribution 4.0 International License. Read Full License 


\section{Abstract}

It remains unclear how competitive exclusion is avoided between two ecologically, economically, and culturally important codominant grass species in the tallgrass prairie of the Great Plains, Andropogon gerardii and Sorghastrum nutans. These functionally similar $\mathrm{C}_{4}$ grasses appear to coexist despite considerable niche overlap, and asymmetric competition and drought tolerance in favor of $A$. gerardii. According to the stress gradient hypothesis, it may be that the sum of interactions between these species, which is typically negative (competitive) due to similar resource requirements, shifts to positive (facilitative) as abiotic stress increases. For instance, if the canopy cover of the stronger competitor reduces losses of subcanopy humidity or shallow soil moisture, recruitment of $S$. nutans tillers may be extended further into the drought event than would occur in the absence of $A$. gerardii. As later months of the growing season are drier on average where these species are codominant, such a mechanism may enable $S$. nutans to recover from early season asymmetric competition and stabilize their codominance. We tested this hypothesis in a greenhouse experiment in which we manipulated community composition and water availability in the latter half of the growing season. We found no evidence that a shift from a negative to positive interaction occurs, with each species performing similarly in mixed communities and monocultures. The similarities of the two species in their functional traits and responses to water limitations may limit such a shift in interaction net effects and suggests that other mechanisms are determining coexistence of these co-occuring $\mathrm{C}_{4}$ grasses.

\section{Introduction}

In the mesic tallgrass prairies of the Great Plains, US, two $\mathrm{C}_{4}$ grass species, Andropogon gerardii Vitman and Sorghastrum nutans (L.) Nash often coexist with such mutually high abundances (canopy cover percentages) $\mathrm{J}$, population densities, and/or occurrence frequencies that they are considered codominant species (sensu (Gray et al., 2021)(L. Brown, 1985; Duralia \& Reader, 1993; Freeman, 1998; Hartnett et al., 1996; Smith \& Knapp, 2003). In most years, these abundances result in high aboveground net primary productivity (ANPP) (Grime, 1998; la Pierre et al., 2011; Smith \& Knapp, 2003), making these species important contributors to ecosystem functioning and services, such as forage for grazing (Vinton et al., 1993), carbon sequestration and storage (Grime, 1998; Kemp et al., 1994; Mahaney et al., 2008; Omonode \& Vyn, 2006), nutrient cycling (Grime, 1998; Mahaney et al., 2008), invasion resistance(Smith et al., 2004), and aesthetic and cultural value. Though the population densities of these two grass species can fluctuate from year to year (Silletti \& Knapp, 2002; Towne \& Kemp, 2003), their codominant relationship has remained stable in the long term. For example, nearly a century ago, Weaver and Fitzpatrick reported abundances similar to those found today in eastern Kansas (Jones et al., 2016; Weaver \& Fitzpatrick, 1932). However, despite their frequent description as codominant species is this region (L. Brown, 1985; Duralia \& Reader, 1993; Freeman, 1998; Hartnett et al., 1996; Smith \& Knapp, 2003), A. gerardii has been reported to be both more competitive for resources (Silletti et al., 2004; Tilman \& Wedin, 1991) and more drought tolerant (Hoffman et al., 2018; Hoffman \& Smith, 2018; Silletti \& Knapp, 2002; Swemmer et al., 2006). 
Given the annually fluctuating population densities of the two species, and the competitive advantages in both wet and dry years attributed to $A$. gerardii, it is not clear how $S$. nutans maintains its role in the codominant relationship over the long term. This uncertainty is further shrouded by the many morphological and physiological similarities borne between A. gerardii and $S$. nutans. These species have multiple life history traits in common, including long-lived genets (Gustafson et al., 2005; Keeler, 2004; Lauenroth \& Adler, 2008; USDA, 2021a, 2021b), C 4 photosynthetic pathways, reproduction mainly through rhizomatous cloning (i.e., ramets/tillers (Benson \& Hartnett, 2006; Lauenroth \& Adler, 2008; McKone et al., 1998; USDA, 2021a, 2021b)), and bear similarities in their functional traits (e.g., leaf dimensions, leaf gas exchange rates, ANPP) (Forrestel et al., 2014, 2015) and responses to fire and grazing disturbances (Weaver, 1931; Weaver and Fitzpatrick, 1932; Hadley and Kieckhefer, 1963; Polley et al., 1992; Towne and Kemp, 2003; Bowles et al., 2011; Forrestel, Donoghue and Smith, 2014, 2015). Both are considered strong competitors under nitrogen limiting conditions (Berg, 1995; Silletti and Knapp, 2001; Lett and Knapp, 2003; Mulkey, Owens and Lee, 2008), and are tall-statured when flowering under mesic conditions (Weaver, 1931; Knapp and Hulbert, 1986), but are intolerant of shading (Weaver and Rowland, 1952; Lett and Knapp, 2003) and persistent grazing (Damhoureyeh \& Hartnett, 2002; Hartnett et al., 1996; Vinton et al., 1993).

Despite all the similarities between the two grasses, the two grasses differ in a key way - in growth determinacy of tillers (McKendrick..) - which may contribute to maintenance of the codominance relationship in space and time (Gray \& Smith, in review). A. gerardii exhibits determinant growth, in which it recruits belowground buds into tillers almost exclusively in the early spring, and these tillers are annual in their lifespan (i.e., senesce in early fall). In contrast, $S$. nutans exhibits indeterminant growth whereby it can recruit belowground buds into tillers throughout the growing season, and later-recruiting tillers can overwinter as belowground buds and be recruited again the following growing season. This difference in growth determinacy results in contrasting intra-seasonal tiller dynamics, in which A. gerardii tiller numbers consistently decline during the growing season whereas $S$. nutans tiller numbers often increase or remain stable. These contrasting population dynamics could have important implications for the stability of codominance of the two species, (Gray \& Smith, in review), and the stress gradient hypothesis is on possible mechanism that may explain how differing growth determinacy may promote stable codominance, particularly within the context of variation in stressful conditions during the growing season.

The stress gradient hypothesis posits that as the intensity of environmental stress increases, the functional sum of the effects of the multiple, simultaneously occurring interactions between competing species becomes less negative as some negative effects are mitigated, and/or the effects of some positive interactions are enhanced, making the presence of certain interspecific and otherwise deleterious neighbors beneficial for survival, growth, and/or reproduction relative to their absence (Bertness \& Callaway, 1994; Brooker \& Callaghan, 1998; Callaway \& Walker, 1997; Olofsson et al., 1999; Ploughe et al., 2018). Alternatively, the two-phase resource dynamics hypothesis (Goldberg \& Novoplansky, 1997) proposes that possibly similar outcomes can occur because resources are typically available in pulses, 
and interactions between plants and their abiotic environment become more important relative to resource competition as resources become less frequent (i.e., become more resource stressed). Such shifts in environmental conditions are common in mesic tallgrass prairie where $A$. gerardii and $S$. nutans codominate. Here, there is a high probability of drought (or dry conditions) occurring during each growing season, despite on average relatively high annual rainfall (Craine et al., 2012; Hayden, 1998; Knight et al., 1994). Drought-associated shifts in net interactions between neighboring species may occur if, for example, a competing species translocates water from deeper to shallower soils through tap roots (i.e., hydraulic lift (Dohn et al., 2013; Joffre \& Rambal, 1988; Weltzin \& Coughenour, 1990)), if a species has physical defense mechanisms that extend protection to neighbors against the exacerbating effects of herbivores (Callaway, 1992; García et al., 2003; McAuliffe, 1986; Vinton et al., 1993), if heavy canopy cover of a species that reduces subcanopy light availability also reduces soil evaporation rates (Escudero et al., 2005; Kikvidze et al., 2006; Pugnaire et al., 2004) or increases humidity within the canopy(Aguirre et al., 2021; Cowles et al., 2016; A. Wright et al., 2014; A. J. Wright et al., 2021), or even if drought-induced mortality in one species increases the availability of resources for the surviving species that may otherwise have been depleted through intra-specific competition (de Dios et al., 2014; Lloret et al., 2004; Ploughe et al., 2018).

Evidence for intra-annual shifts between net negative vs. positive interactions has been observed in codominant species under stressful conditions induced by water limitation later in the growing season. For example, two codominant plant species in a subalpine environment were reported to shift between overall competitive to facilitative relationships as water availability regularly declined during the latter weeks of growing seasons of each year (Kikvidze et al., 2006). In their report, the authors attributed negative interactions in the early season to competition for light. This negative effect was reduced as precipitation declined and leaf cover decreased, and it was speculated that soil moisture may also have been conserved in the mixed communities compared to monocultures. Similarly, such shift in the sum of interaction effects between $A$. gerardii and $S$. nutans, may be a mechanism responsible the stability of their codominant relationship. That is, if $S$. nutans, purportedly the less competitive and drought tolerant of the two species (Hoffman et al., 2018; Hoffman \& Smith, 2018; Silletti et al., 2004; Silletti \& Knapp, 2002; Swemmer et al., 2006), benefits from the presence neighboring $A$. gerardii individuals (relative to intra-specific ones) in the drier months of the growing season, the presence of $A$. gerardii individuals may increase the fitness of $S$. nutans during that time and reduce the probability of its competitive exclusion. Moreover, because $S$. nutans is able to recruit new tillers throughout the growing season while A. gerardii is not (McKendrick et al., 1975), drought-driven senescence of $A$. gerardii may facilitate the emergence and growth of young $S$. nutans tillers by opening gaps in the canopy for light to reach the understory, allowing $S$. nutans populations to increase in density and recover from the asymmetry of competition suffered during the early season.

To test whether stressful conditions induced by late-season drought can shift the overall relationship between $A$. gerardii and $S$. nutans to one that is more facilitative, we performed a controlled greenhouse experiment using artificial communities. We compared the performance of these species in communities with interspecific mixes to those with only intraspecific neighbors. Using a simple response surface 
design, we tested the following hypotheses: 1) Water limitation (stress) would diminish the per capita performance of both species at both low and high community densities; 2) Increased community density would reduce per capita performance of each species in monoculture at both high and low water availability levels; 3 ) In accordance with the stress-gradient hypothesis, interspecific neighbors would alleviate a portion of the negative effects of water limitation relative to monocultures at a given total community genet density.

\section{Methods}

We established artificial communities of varying densities from wild-collected seeds of $A$. gerardii and $S$. nutans (Star Seed Inc, Osborne KS). Community treatments included low (15 genets) and high (30 genets) density monocultures of each species, and a high total density mixture (15 genets of each species, 30 total genets) in 1-gallon pots and 3L of Pro-Mix High Porosity Biofungicide + Mycorrhizae potting soil, with ten replicates of each of the eight community combination treatments. The selected genet densities were within a range previously observed in a physically undisturbed, but annually burned lowland area where the species are codominant (unpublished data). To ensure sufficient germination, an excess of seeds of each species were spread randomly across soil surfaces and buried under $10 \mathrm{~mm}$ of potting soil. Once the successful germinants were identifiable to species, their surpluses were removed by hand, primarily from the perimeters of the pots to ensure that the remaining seedlings matched the target density and that no individuals were isolated from the community. Once most of the seedlings had produced their third leaves, $15 \mathrm{~mL}$ of Osmocote Plus extended-release fertilizer was added to each of the pots. The communities were closely monitored over the course of the experiment for any new germinants, and these individuals were removed upon detection.

Each of the community combination replicates was placed randomly within the greenhouse space and provided a minimum of 12 hours of sunlight daily. All the pots were rotated once every four days to reduce any biasing effects of variable light availability or microclimate conditions (Fig. S1)

For the first 78 days after seeding, all community combination replicates received $0.5 \mathrm{~L}$ of water once every other day to simulate well-watered conditions. This volume fully saturated the soil, and excess water was able to drain. At the end of this 78-day period, all the clonal offspring (i.e., ramets) of the original seedlings (i.e., genets) were counted. Following this two-day survey, half of the replicates were randomly selected to receive a watering frequency unaltered from the early season (control treatment), while the frequency of watering for the remaining replicates was reduced by half (drought treatment). The goal of the drought treatment was to simulate the late-season dry conditions that often occur under natural field conditions (Hayden, 1998). In a pilot study, both species were observed to have reduced ANPP and population growth rates at the lower watering rates (Gray, data not shown). Average soil moisture measurements (volumetric water content, VWC) were taken prior to and following each watering event using a hand-held soil moisture probe (Campbell Scientific, Logan UT). Immediately after watering, the soils in both treatments had similar VWC (38\%, averaged across watering events and treatments), but had dissimilar VWC prior to watering (average of $20.8 \%$ VWC for the control and $7.4 \%$ for the drought 
treatments). By the middle of the late season, drought-treated $S$. nutans monoculture pots were observed to hold less water (average 18\% post-event), but also to dry less quickly (average 10\% pre-event). After 18 days, the drought-treated pots were observed to have less canopy cover (Fig. S1A), and so were grouped together to avoid excessive shading from the control treatment pots. The pot rotation schedule was resumed after this rearrangement. (Fig. S1B)

A second ramet density survey was conducted at the end of the experiment (day 151) with living and senesced individuals counted separately. Daily watering was applied to all communities over the five days of the survey and two days prior to facilitate correct distinction between living and dead ramets. All aboveground biomass was clipped from each pot at the soil surface after it had been surveyed for ramet density. The biomass was sorted to species, dried in a heating oven at $60^{\circ} \mathrm{C}$ for 48 hours, and weighed to determine ANPP.

\section{Statistical analysis}

We compared performances of the different community combination and watering treatments in terms of three metrics considered relevant for long-term population dynamics and facilitation (e.g., Bronstein, 2009; J. H. Brown et al., 2004; Silvertown et al., 1993): 1) survivability, measured as the fraction of ramets recruited since the beginning of the experiment that maintained living leaf tissue until the date of the second (final) survey; 2 ) reproductive rate, measured as the total number of ramets produced per genet over the course of the experiment; and 3) ANPP, measured as the average amount of aboveground biomass produced per genet, including the aggregate biomass of their ramets.

To test the hypothesis that the late season drought treatment would reduce each species' per capita performance at both low and high monoculture densities, we compared the performance metrics of monocultures receiving the late season drought to monocultures of equal genet densities receiving the control watering treatment. We used Wilcoxon rank sum tests $\left(\mathrm{H}_{0}\right.$ : Drought treatment has positive or no effect on per capita performance) to make these comparisons. The tests were run separately for each species and for each monoculture density and corrected for multiple comparisons using Bonferroni adjustments and four degrees of freedom ( 12 comparisons in total ( 2 species * 3 metrics * 2 densities), alpha adjusted to 0.0042).

To test the hypothesis that increased monoculture density would reduce per capita performance of genets, we compared each of the performance metrics between monocultures consisting of 15 genets to those with 30 genets using Wilcoxon rank sum tests $\left(\mathrm{H}_{0}\right.$ : positive or no effect of increased density on performance). This was done separately for each species and for the drought and control treatments and corrected for multiple comparisons ( 12 total: 2 species * 3 metrics * 2 watering frequencies) using Bonferroni adjustments and four degrees of freedom (alpha adjusted to 0.0042).

To test the hypothesis that interspecific neighbors would mitigate a portion of the negative effects of environmental stress, we compared performance metrics of drought-treated monoculture communities with 30 genets to drought-treated mixed communities consisting of 15 genets of each species. We used 
Wilcoxon rank sum tests $\left(\mathrm{H}_{0}\right.$ : Negative effect of interspecific neighbors or no difference in performance between communities) to make these comparisons. Bonferroni adjustments were made to correct for multiple comparisons and four degrees of freedom (Six comparisons in total, alpha adjusted to 0.0083 ).

In the interest of highlighting factor effect differences, we calculated the effect sizes of each of the factors described above (drought, density, and interspecific neighbors in drought at high density) in terms of Hedge's q. This was done for both species and for each of the performance metrics. Confidence intervals were corrected to account for the multiple comparisons related to each hypothesis using Bonferroni adjustments.

While mixed communities may not always mitigate the negative effects of late season drought to the degree that the sum of their interactions become positive, it is possible that the sum becomes less negative under stressed abiotic conditions in comparison to highly competitive environments. To determine whether the mixed community treatment caused interactions between community members to be less negative under the drought treatment than in the control treatment, we calculated the relative neighbor effect (RNE) for the 30-genet mixed communities and 30-genet monocultures as described in Kikvidze et al. (2006):

$\mathrm{RNE}=(C-T) / \max (C, T)$

where refers to the per capita performance metric (i.e., survivability, reproductive output, or ANPP, averaged across replicates) of the focal species in a mixed community, and refers to the respective metric for the focal species in monoculture. When RNE is positive, it indicates that the performance of the focal species was facilitated by the presence of the interspecific neighbor, but a negative RNE indicates that the interspecific neighbor was more detrimental to the performance of the focal species than intraspecific neighbors at the same density. We then compared the RNE between the control and the drought treated communities for each species to determine if the stress of the imposed drought caused RNE to become relatively less negative.

\section{Results}

The drought treatment resulted in significant reductions in ANPP per genet of $A$. gerardii $(41.0 \%$ mean reduction) and survival rates of $A$. gerardii ramets (42.3\% mean reduction) within 30-genet, but not 15genet monocultures (Fig. 1a-c). Likewise, the effect size (Hedge's q) of the drought treatment on ramet survival rate was significantly less than zero for the 30-genet monoculture, though the confidence interval for the effect of drought on ANPP included zero. The reproduction rate of $A$. gerardii ramets was not affected by drought at either the low or high genet densities.

Drought significantly reduced per genet ANPP of $S$. nutans in both 15 -genet (32.3\% mean reduction) and 30 -genet monocultures $(27.5 \%$ mean reduction, Fig. 1 d). Trends toward reductions in ramet production 
rates in 15-genet monocultures and ramet survival rates in both genet densities were also observed, but these differences were not significant after adjusting for multiple comparisons, nor were the effect sizes significantly less than zero (Fig. 1e-f). No effect of drought was observed for the rate of $S$. nutans ramet production at the 30-genet density (Fig. 1e).

The comparison between droughted 30-genet monocultures and 30-genet mixed communities did not uncover any significant differences in any of the performance metrics of either species (Fig. 2), nor did any of the effect sizes differ significantly from zero. There was a trend towards reduced ANPP of $A$. gerardii in the mixed community compared to its monoculture, but this difference was not significant after adjusting for multiple comparisons.

In most cases, our calculations of relative neighbor effect (RNE) found no significant difference between mixed and monoculture communities (Fig. 3), suggesting that neither $S$. nutans nor A. gerardii were typically facilitated by interspecific neighbor whether in the control or drought treatment. Further, the rate of $S$. nutans clonal reproduction was significantly lower in mixed communities under drought than in the monoculture, and the ANPP of $A$. gerardii was significantly lower in communities with $S$. nutans than in monocultures. This result was not universal however, as $S$. nutans per capita ANPP was greater in the mixed communities, though the respective $95 \%$ confidence intervals narrowly overlapped with zero, indicating no significant difference between mixed communities and monocultures. Moreover, there were no significant differences between RNE values in the control and drought treatments for any performance metric in either species (Table S1).

\section{Discussion}

We found that for the codominant grass species, A. gerardii and S. nutans, at least one aspect of performance (ANPP per genet, survival rate of ramets, or clonal reproduction rate per genet) declined either as a result of increasing intraspecific genet density, late-season drought, or both (Fig. 1), in agreement with our first and second hypotheses. While our expectation - that increasing density of identical competitors would result in more negative net interactions - was confirmed by this study (Fig. 1), the effects of the density and drought treatments differed for each of the performance metrics. The drought treatment primarily affected ANPP in both species (Fig. 1), confirming our expectation that late season water limitation can indeed be a stress factor for both species that results in diminished performance. However, the lesser effects on ramet reproduction rates and survivability suggests that the drought treatment did not simulate extreme conditions (Smith, 2011), and that the degree of water limitation imposed on these species was not outside the range of conditions they are capable of surviving. Ramet survivability was only significantly affected in the higher genet density $A$. gerardii populations (Fig. 1c). In contrast, ANPP of both species was negatively affected by both increasing genet densities in monocultures and by drought (Figs 1a, d). As might be expected from longlived species, this suggests that survivability is the more valued trait for maintaining the long-term demographic stability of both these perennial species, with sacrifices in ANPP being preferable to premature senescence (Obeso, 2002a). While ramet death does not necessarily result in genet death, early 
senescence diminishes genet resource control and hinders meristem development, resulting in lost opportunities for the ramet production that ultimately sustains genet (and population) longevity (Hartnett \& Bazzaz, 1985; Hutchings \& Wijesinghe, 1997; Jeník, 1994; Matsuo et al., 2018). Population growth per genet of $S$. nutans, but not of $A$. gerardii was also significantly reduced by increasing monoculture density under both watering treatments, suggesting that ramet survivability is prioritized for $S$. nutans over asexual reproduction as intraspecific competition increases. Because $A$. gerardii exhibits determinate growth and typically early-season-only generation of annual ramets (McKendrick et al., 1975), intraspecific density effects may have less of an impact on that species' asexual reproduction and longterm population dynamics than on $S$. nutans, which is biennial (produces over-wintering ramets in the late season) and reproduces indeterminately (McKendrick et al., 1975). However, it is not yet clear how lateseason droughts or intraspecific densities affect overwintering belowground bud banks and the initiation of next-season tillering of either species.

In contrast to the stress gradient hypothesis, we did not find evidence that $S$. nutans populations experiencing late-season soil water deficits are facilitated by $A$. gerardii neighbors. Instead, we observed that reductions of both $A$. gerardii and $S$. nutans performance associated with drought conditions did not differ significantly when comparing monocultures to equal-density species mixtures (Fig. 2, 3). These findings are in remarkably close agreement with those of Duralia and Reader (1993), who found in seeding and removal experiments that while competitor density reduces the field performance of $A$. gerardii, S. nutans, and a third perennial grass species, Dicanthelium oligosanthes, the identity of the competitor, whether intra- or interspecific, was of little consequence. The present study extends these findings by showing that these overall competitive relationships can persist despite water stress.

Our evaluation of relative neighbor effect (RNE) found that the values for $S$. nutans most often overlapped with zero, with the exception that per capita ramet recruitment under drought conditions was significantly reduced when communities included $A$. gerardii genets (Fig. 3 ). That ramet survival rates and ANPP were not similarly affected by $A$. gerardii under drought conditions is suggestive of a reallocation of resources away from reproduction and towards survival and competitive resource capture when in mixed communities. Such plastic reallocations of investments between vegetative growth and reproductive structures are commonly examined, but with mixed findings (Gardner \& Mangel, 1999; Gioria \& Osborne, 2014; Guo et al., 2020; Kumari et al., 2020; Liu et al., 2021; Obeso, 2002b; Tonnabel et al., 2017). Since $S$. nutans ramets are biennial or longer lived, reproductive opportunities may remain open if ramet survival is ensured. While average $S$. nutans RNE values for ANPP were positive, an observation suggesting facilitation, they could not, by a narrow margin, be statistically distinguished from zero. Additional replicates would likely clarify this relationship. Nevertheless, there was no difference in RNE between the control and drought treatments for $S$. nutans ANPP, so while facilitation may occur, we did not find support for the hypothesis that environmental stress alters net interactions associated with ANPP of these species. Instead, it may be that $S$. nutans is favoring aboveground allocation of resources at the expense of roots when in proximity with $A$. gerardii, perhaps to better compete for light, another plastic response to competition and resource limitation that has previously been reported (Franzese \& 
Ghermandi, 2014; Martina \& von Ende, 2012; Maurer \& Zedler, 2002; Robakowski et al., 2018). However, since we did not measure belowground productivity, we cannot confirm whether this happened or not.

The RNE values for $A$. gerardii were always significantly negative (ramet survival rates in control conditions, ANPP in control and drought) or overlapping with zero (Fig. 3), indicating that the effects of $S$. nutans neighbors were either detrimental relative to those of $A$. gerardii neighbors, or they could not be distinguished from intra-specific effects. Moreover, as with $S$. nutans, there was no difference in RNE between control and drought conditions for any of the performance metrics of $A$. gerardii. While it is possible that the drought conditions imposed were too extreme (or not extreme enough) to allow interactions between the species to shift (in aggregate), which would reflect the patterns observed at low or high rates of stress in already stressful environments (e.g., arid ecosystems (Maestre et al., 2005)), the similarity of RNE values between control and drought treatments in both species and the general failure of the drought to cause severe reductions in either rates of ramet survival or ramet reproduction in either species (Fig. 1) does not support this notion. Nor does the fact that the drought treatment reduced ANPP, which suggests water limitation was substantial enough to limit growth.

The two subalpine species presented by Kikvidze et al. (2006) that annually experience shifts in cumulative interactions from net competitive to net facilitative during the drier late seasons included a perennial $\mathrm{C}_{3}$ bunchgrass (Hordeum violaceum) and a perennial leguminous forb (Trifolium abiguum). The species presented in our study, both rhizomatous $\mathrm{C}_{4}$ grasses, are at least superficially more similar to one another in comparison. Given the morphological and physiological similarities of $A$. gerardii and $S$. nutans, and the functional similarity of their responses to water stress in particular, our observations suggest that shifts towards net positive interspecific interactions under increasing environmental stress may be limited by the functional similarity of those species. Indeed, when taken to an extreme, if two species share an identical response to some form of stress, then no advantage can be expected by having interspecific rather than intraspecific neighbors as the severity of that stress increases (Eränen \& Kozlov, 2009; Fajardo \& Mclntire, 2011). Thus, shifts from net negative to net positive may be hindered not only by a breakdown of certain positive interactions as environmental stress approaches extremes, but the similarities in the ways that species respond to stress may also place limits on the range of net interactions between species and their associated capacities for stabilizing their coexistence in fluctuating environments (Chesson, 2000; Maestre et al., 2009). Thus, considerations of functional traits and their relationships with species responses to stress should enhance understanding of species interactions across stress gradients (Fig. 4 (Butterfield \& Callaway, 2013)).

Our finding that the typically negative (competitive) species interactions between $A$. gerardii and $S$. nutans appear to remain so (or perhaps become more negative) under more stressful (dry) conditions suggests that the frequently observed codominance between these species are facilitated by mechanisms other than periodic stress-driven shifts in net interaction signs. In contrast to the findings of others, rather than receiving temporary relief from competition brought about by stressful environmental conditions, we suspect that competitive exclusion can be as likely or more so under stress, depending on the severity of the stress and the similarity of the species responses to it. As such, we caution against 
overconfidence in interactive stress mitigation as a mechanism for maintaining biodiversity in variable environments when the species involved bear substantial functional similarities in their responses to that variability, though it is possible that our methodology was less powerful than in situ removal experiments for detecting shifts in interaction types (He et al., 2013). More remains to be investigated, including the potential for mitigation of other forms of stress (e.g., heat, flooding, herbivory), the effects of stress during different periods of the growing season (i.e., early season, mid-season), and the effects of stress occurring across different time scales (i.e., interannual). However, given climate-change-associated projections of increasing intra- and interannual frequency of drought conditions in regions where $A$. gerardii and S. nutans are currently codominant (Cook et al., 2015), the long-term stability of their populations should be fully considered. Further study using consistent methodologies into the variability of net interactions between plant species across a gradient of similarities in traits and responses to stress is also strongly recommended.

\section{Declarations}

\section{Data availability statement}

Data supporting the findings of this study are available through the Environmental Data Initiative.

\section{Author contributions}

JEG conceived and designed the study and collected and analyzed the data. JEG and MDS wrote the manuscript.

\section{Competing interests}

The authors have no relevant financial or non-financial interests to disclose.

\section{References}

1. Aguirre, B. A., Hsieh, B., Watson, S. J., \& Wright, A. J. (2021). The experimental manipulation of atmospheric drought: Teasing out the role of microclimate in biodiversity experiments. Journal of Ecology, 109(5), 1986-1999. https://doi.org/10.1111/1365-2745.13595

2. Benson, E. J., \& Hartnett, D. C. (2006). The Role of Seed and Vegetative Reproduction in Plant Recruitment and Demography in Tallgrass Prairie. Plant Ecology, 187(2), 163-178. https://doi.org/10.1007/s11258-005-0975-y

3. Bertness, M. D., \& Callaway, R. M. (1994). Positive interactions in communities. Trends in Ecology \& Evolution, 9(5), 191-193. https://doi.org/10.1016/0169-5347(94)90088-4

4. Bronstein, J. L. (2009). The evolution of facilitation and mutualism. Journal of Ecology, 97(6), 11601170. https://doi.org/10.1111/j.1365-2745.2009.01566.x 
5. Brooker, R. W., \& Callaghan, T. v. (1998). The Balance between Positive and Negative Plant Interactions and Its Relationship to Environmental Gradients: A Model. Oikos, 81(1), 196. https://doi.org/10.2307/3546481

6. Brown, J. H., Gillooly, J. F., Allen, A. P., Savage, V. M., \& West, G. B. (2004). TOWARD A METABOLIC THEORY OF ECOLOGY. Ecology, 85(7), 1771-1789. https://doi.org/10.1890/03-9000

7. Brown, L. (1985). The Audobon Society Nature Guides: Grasslands. Alfred A. Knopf, Inc.

8. Butterfield, B. J., \& Callaway, R. M. (2013). A functional comparative approach to facilitation and its context dependence. Functional Ecology, 27(4), 907-917. https://doi.org/10.1111/1365-2435.12019

9. Callaway, R. M. (1992). Effect of Shrubs on Recruitment of Quercus Douglasii and Quercus Lobata in California. Ecology, 73(6), 2118-2128. https://doi.org/10.2307/1941460

10. Callaway, R. M., \& Walker, L. R. (1997). Competition and facilitation: A synthetic approach to interactions in plant communities. Ecology, 78(7), 1958-1965. https://doi.org/10.1890/00129658(1997)078[1958:CAFASA]2.0.C0;2

11. Chesson, P. (2000). Mechanisms of maintenance of species diversity. Annual Review of Ecology and Systematics, 31(1), 343-366. https://doi.org/10.1146/annurev.ecolsys.31.1.343

12. Cook, B. I., Ault, T. R., \& Smerdon, J. E. (2015). Unprecedented 21 st century drought risk in the American Southwest and Central Plains. Science Advances, 1(1), e1400082. https://doi.org/10.1126/sciadv.1400082

13. Cowles, J. M., Wragg, P. D., Wright, A. J., Powers, J. S., \& Tilman, D. (2016). Shifting grassland plant community structure drives positive interactive effects of warming and diversity on aboveground net primary productivity. Global Change Biology, 22(2), 741-749. https://doi.org/10.1111/GCB.13111

14. Craine, J. M., Nippert, J. B., Elmore, A. J., Skibbe, A. M., Hutchinson, S. L., \& Brunsell, N. A. (2012). Timing of climate variability and grassland productivity. Proceedings of the National Academy of Sciences of the United States of America, 109(9), 3401-3405. https://doi.org/10.1073/pnas.1118438109

15. Damhoureyeh, S. A., \& Hartnett, D. C. (2002). Variation in grazing tolerance among three tallgrass prairie plant species. American Journal of Botany, 89(10), 1634-1643. https://doi.org/10.3732/ajb.89.10.1634

16. de Dios, V. R., Weltzin, J. F., Sun, W., Huxman, T. E., \& Williams, D. G. (2014). Transitions from grassland to savanna under drought through passive facilitation by grasses. Journal of Vegetation Science, 25(4), 937-946. https://doi.org/10.1111/JVS.12164

17. Dohn, J., Dembélé, F., Karembé, M., Moustakas, A., Amévor, K. A., \& Hanan, N. P. (2013). Tree effects on grass growth in savannas: competition, facilitation and the stress-gradient hypothesis. Journal of Ecology, 101(1), 202-209. https://doi.org/10.1111/1365-2745.12010

18. Duralia, T. E., \& Reader, R. J. (1993). Does Abundance Reflect Competitive Ability?: A Field Test with Three Prairie Grasses. Oikos, 68(1), 82. https://doi.org/10.2307/3545312

19. Eränen, J. K., \& Kozlov, M. V. (2009). Interactions between mountain birch seedlings from differentiated populations in contrasting environments of subarctic Russia. Plant Ecology, 200(2), 
167-177. https://doi.org/10.1007/s11258-008-9441-y

20. Escudero, A., Romão, R. L., de La Cruz, M., \& Maestre, F. T. (2005). Spatial pattern and neighbour effects on Helianthemum squamatum seedlings in a Mediterranean gypsum community. Journal of Vegetation Science, 16(4), 383-390. https://doi.org/10.1111/J.1654-1103.2005.TB02377.X

21. Fajardo, A., \& McIntire, E. J. B. (2011). Under strong niche overlap conspecifics do not compete but help each other to survive: facilitation at the intraspecific level. Journal of Ecology2, 99(2), 642-650.

22. Forrestel, E. J., Donoghue, M. J., \& Smith, M. D. (2014). Convergent phylogenetic and functional responses to altered fire regimes in mesic savanna grasslands of North America and South Africa. New Phytologist, 203(3), 1000-1011. https://doi.org/10.1111/nph.12846

23. Forrestel, E. J., Donoghue, M. J., \& Smith, M. D. (2015). Functional differences between dominant grasses drive divergent responses to large herbivore loss in mesic savanna grasslands of North America and South Africa. Journal of Ecology, 103(3), 714-724. https://doi.org/10.1111/13652745.12376

24. Franzese, J., \& Ghermandi, L. (2014). Early competition between the exotic herb Rumex acetosella and two native tussock grasses with different palatability and water stress tolerance. Journal of Arid Environments, 106, 58-62. https://doi.org/10.1016/J.JARIDENV.2014.03.004

25. Freeman, C. C. (1998). The flora of Konza Prairie: a historical review and contemporary patterns. Oxford University Press.

26. García, D., Ramón, J., García, O., García, D., \& Obeso, J. R. (2003). Facilitation by herbivore-mediated nurse plants in a threatened tree, Taxus baccata: local effects and landscape level consistency. Ecography, 26(6), 739-750. https://doi.org/10.1111/J.0906-7590.2003.03601.X

27. Gardner, S. N., \& Mangel, M. (1999). Modeling investments in seeds, clonal offspring, and translocation in a clonal plant. Ecology, 80(4), 1202-1220. https://doi.org/10.2307/177068

28. Gioria, M., \& Osborne, B. A. (2014). Resource competition in plant invasions: Emerging patterns and research needs. Frontiers in Plant Science, 5(SEP), 501.

https://doi.org/10.3389/FPLS.2014.00501/BIBTEX

29. Goldberg, D., \& Novoplansky, A. (1997). On the Relative Importance of Competition in Unproductive Environments. The Journal of Ecology, 85(4), 409. https://doi.org/10.2307/2960565

30. Gray, J. E., Komatsu, K. J., \& Smith, M. D. (2021). Defining codominance in plant communities. New Phytologist, 230(5), 1716-1730. https://doi.org/10.1111/NPH.17253

31. Grime, J. P. (1998). Benefits of plant diversity to ecosystems: immediate, filter and founder effects. Journal of Ecology, 86(6), 902-910. https://doi.org/10.1046/j.1365-2745.1998.00306.x

32. Guo, J., Li, H., \& Yang, Y. (2020). Phenotypic Plasticity in Sexual Reproduction Based on Nutrients Supplied From Vegetative Ramets in a Leymus chinensis Population. Frontiers in Plant Science, 10, 1681. https://doi.org/10.3389/FPLS.2019.01681/BIBTEX

33. Gustafson, D. J., Gibson, D. J., \& Nickrent, D. L. (2005). Using local seeds in prairie restoration-data support the paradigm. Native Plants Journal, 6(1), 25-28. https://doi.org/10.1353/NPJ.2005.0022 
34. Hartnett, D. C., \& Bazzaz, F. A. (1985). The genet and ramet population dynamics of Solidago canadensis in an abandoned field. Journal of Ecology, 73, 407-413.

35. Hartnett, D. C., Hickman, K. R., \& Walter, L. E. F. (1996). Effects of Bison Grazing, Fire, and Topography on Floristic Diversity in Tallgrass Prairie. Journal of Range Management, 49(5), 413. https://doi.org/10.2307/4002922

36. Hayden, B. P. (1998). Regional climate and the distribution of tallgrass prairie. In Long-Term Ecological Research in Tallgrass Prairie (pp. 19-34).

37. He, Q., Bertness, M. D., \& Altieri, A. H. (2013). Global shifts towards positive species interactions with increasing environmental stress. Ecology Letters, 16(5), 695-706.

https://doi.org/10.1111/ELE.12080

38. Hoffman, A. M., Avolio, M. L., Knapp, A. K., \& Smith, M. D. (2018). Codominant grasses differ in gene expression under experimental climate extremes in native tallgrass prairie. PeerJ, 6, e4394. https://doi.org/10.7717/peerj.4394

39. Hoffman, A. M., \& Smith, M. D. (2018). Gene expression differs in codominant prairie grasses under drought. Molecular Ecology Resources, 18(2), 334-346. https://doi.org/10.1111/1755-0998.12733

40. Hutchings, M. J., \& Wijesinghe, D. K. (1997). Patchy habitats, division of labour and growth dividends in clonal plants. Trends in Ecology \& Evolution, 12(10), 390-394. https://doi.org/10.1016/S01695347(97)87382-X

41. Jeník, J. (1994). Clonal growth in woody plants: A review. Folia Geobotanica et Phytotaxonomica, 29(2), 291-306. https://doi.org/10.1007/BF02803802

42. Joffre, R., \& Rambal, S. (1988). Soil-water improvement by trees in the rangelands of Southern Spain. Acta Oecologica, 9, 405-422.

43. Jones, S. K., Collins, S. L., Blair, J. M., Smith, M. D., \& Knapp, A. K. (2016). Altered rainfall patterns increase forb abundance and richness in native tallgrass prairie. Scientific Reports 2016 6:1, 6(1), 110. https://doi.org/10.1038/srep20120

44. Keeler, K. H. (2004). Impact of Intraspecific Polyploidy in Andropogon gerardii (Poaceae) Populations. The American Midland Naturalist, 152(1), 63-74. https://doi.org/10.1674/0003

45. Kemp, P. R., Waldecker, D. G., Owensby, C. E., Reynolds, J. F., \& Virginia, R. A. (1994). Effects of elevated $\mathrm{CO} 2$ and nitrogen fertilization pretreatments on decomposition on tallgrass prairie leaf litter. Plant and Soil 1994 165:1, 165(1), 115-127. https://doi.org/10.1007/BF00009968

46. Kikvidze, Z., Khetsuriani, L., Kikodze, D., \& Callaway, R. M. (2006). Seasonal shifts in competition and facilitation in subalpine plant communities of the central Caucasus. Journal of Vegetation Science, 17(1), 77-82. https://doi.org/10.1111/j.1654-1103.2006.tb02425.x

47. Knight, C. L., Briggs, J. M., \& Nellis, M. D. (1994). Expansion of gallery forest on Konza Prairie Research Natural Area, Kansas, USA. In Landscape Ecology (Vol. 9, Issue 2). SPB Academic Publishing bv. https://doi.org/10.1007/BF00124378

48. Kumari, R., Hamal, U., \& Sharma, N. (2020). Resource Allocation in Flowering Plants: Concept and Implications. Reproductive Ecology of Flowering Plants: Patterns and Processes, 157-171. 
https://doi.org/10.1007/978-981-15-4210-7_8

49. Ia Pierre, K. J., Yuan, S., Chang, C. C., Avolio, M. L., Hallett, L. M., Schreck, T., \& Smith, M. D. (2011). Explaining temporal variation in above-ground productivity in a mesic grassland: the role of climate and flowering. Journal of Ecology, 99(5), 1250-1262. https://doi.org/10.1111/J.13652745.2011.01844.X

50. Lauenroth, W. K., \& Adler, P. B. (2008). Demography of perennial grassland plants: survival, life expectancy and life span. Journal of Ecology, 96(5), 1023-1032. https://doi.org/10.1111/J.13652745.2008.01415.X

51. Liu, L., Zuo, S., Ma, M., Li, J., Guo, L., \& Huang, D. (2021). Appropriate nitrogen addition regulates reproductive strategies of Leymus chinensis. Global Ecology and Conservation, 27, e01599. https://doi.org/10.1016/J.GECCO.2021.E01599

52. Lloret, F., Siscart, D., \& Dalmases, C. (2004). Canopy recovery after drought dieback in holm-oak Mediterranean forests of Catalonia (NE Spain). Global Change Biology, 10(12), 2092-2099. https://doi.org/10.1111/J.1365-2486.2004.00870.X

53. Maestre, F. T., Callaway, R. M., Valladares, F., \& Lortie, C. J. (2009). Refining the stress-gradient hypothesis for competition and facilitation in plant communities. Journal of Ecology, 97(2), 199205. https://doi.org/10.1111/J.1365-2745.2008.01476.X

54. Maestre, F. T., Valladares, F., \& Reynolds, J. F. (2005). Is the change of plant - plant interactions with abiotic stress predictable? A meta-analysis of field results in arid. 748-757. https://doi.org/10.1111/j.1365-2745.2005.01017.x

55. Mahaney, W. M., Smemo, K. A., \& Gross, K. L. (2008). Impacts of C4 grass introductions on soil carbon and nitrogen cycling in C3-dominated successional systems. Oecologia, 157(2), 295-305. https://doi.org/10.1007/S00442-008-1063-5/FIGURES/4

56. Martina, J. P., \& von Ende, C. N. (2012). Highly plastic response in morphological and physiological traits to light, soil-N and moisture in the model invasive plant, Phalaris arundinacea. Environmental and Experimental Botany, 82, 43-53. https://doi.org/10.1016/J.ENVEXPBOT.2012.03.010

57. Matsuo, A., Tomimatsu, H., Sangetsu, Y., Suyama, Y., \& Makita, A. (2018). Genet dynamics of a regenerating dwarf bamboo population across heterogeneous light environments in a temperate forest understorey. Ecology and Evolution, 8(3), 1746-1757. https://doi.org/10.1002/ece3.3793

58. Maurer, D. A., \& Zedler, J. B. (2002). Differential invasion of a wetland grass explained by tests of nutrients and light availability on establishment and clonal growth. Oecologia 2002 131:2, 131(2), 279-288. https://doi.org/10.1007/S00442-002-0886-8

59. McAuliffe, J. R. (1986). Herbivore-limited establishment of a Sonoran Desert tree, Cercidium microphyllum. Ecology, 67(1), 276-280. https://doi.org/10.2307/1938533

60. McKendrick, J. D., Owensby, C. E., \& Hyde, R. M. (1975). Big bluestem and indiangrass vegetative reproduction and annual reserve carbohydrate and nitrogen cycles. Agro-Ecosystems, 2(1), 75-93. https://doi.org/10.1016/0304-3746(75)90007-4 
61. McKone, M. J., Lund, C. P., \& O’Brien, J. M. (1998). Reproductive biology of two dominant prairie grasses (Andropogon gerardii and Sorghastrum nutans, Poaceae): Male-biased sex allocation in wind-pollinated plants? American Journal of Botany, 85(6), 776-783.

https://doi.org/10.2307/2446412

62. Obeso, J. R. (2002a). The costs of reproduction in plants. New Phytologist, 155(3), 321-348. https://doi.org/10.1046/j.1469-8137.2002.00477.x

63. Obeso, J. R. (2002b). The costs of reproduction in plants. New Phytologist, 155(3), 321-348. https://doi.org/10.1046/J.1469-8137.2002.00477.X

64. Olofsson, J., Moen, J., \& Oksanen, L. (1999). On the Balance between Positive and Negative Plant Interactions in Harsh Environments. Oikos, 86(3), 539. https://doi.org/10.2307/3546658

65. Omonode, R. A., \& Vyn, T. J. (2006). Vertical distribution of soil organic carbon and nitrogen under warm-season native grasses relative to croplands in west-central Indiana, USA. Agriculture, Ecosystems \& Environment, 117(2-3), 159-170. https://doi.org/10.1016/J.AGEE.2006.03.031

66. Ploughe, L. W., Jacobs, E. M., Frank, G. S., Greenler, S. M., Smith, M. D., \& Dukes, J. S. (2018). Community Response to Extreme Drought (CRED): a framework for drought-induced shifts in plantplant interactions. New Phytologist. https://doi.org/10.1111/nph.15595

67. Pugnaire, F. I., Armas, C., \& Valladares, F. (2004). Soil as a mediator in plant-plant interactions in a semi-arid community. Https://Doi.Org/10.1658/1100-9233(2004)015[0085:SAAMIP]2.0.C0;2, 15(1), 85-92. https://doi.org/10.1658/1100-9233(2004)015

68. Robakowski, P., Bielinis, E., \& Sendall, K. (2018). Light energy partitioning, photosynthetic efficiency and biomass allocation in invasive Prunus serotina and native Quercus petraea in relation to light environment, competition and allelopathy. Journal of Plant Research, 131(3), 505-523. https://doi.org/10.1007/S10265-018-1009-X/FIGURES/6

69. Silletti, A. M., \& Knapp, A. K. (2002). Long-term responses of the grassland co-dominants Andropogon gerardii and Sorghastrum nutans to changes in climate and management. Plant Ecology, 163(1), 15-22. https://doi.org/10.1023/A:1020320214750

70. Silletti, A. M., Knapp, A. K., \& Blair, J. M. (2004). Competition and coexistence in grassland codominants: responses to neighbour removal and resource availability. Canadian Journal of Botany, 82(4), 450-460. https://doi.org/10.1139/b04-016

71. Silvertown, J., Franco, M., Pisanty, I., \& Mendoza, A. (1993). Comparative Plant Demography-Relative Importance of Life-Cycle Components to the Finite Rate of Increase in Woody and Herbaceous Perennials. The Journal of Ecology, 81(3), 465. https://doi.org/10.2307/2261525

72. Smith, M. D. (2011). An ecological perspective on extreme climatic events: a synthetic definition and framework to guide future research. Journal of Ecology, 99(3), 656-663. https://doi.org/10.1111/j.1365-2745.2011.01798.x

73. Smith, M. D., \& Knapp, A. K. (2003). Dominant species maintain ecosystem function with nonrandom species loss. Ecology Letters, 6(6), 509-517. https://doi.org/10.1046/j.14610248.2003.00454.x 
74. Smith, M. D., Wilcox, J. C., Kelly, T., \& Knapp, A. K. (2004). Dominance not richness determines invasibility of tallgrass prairie. Oikos, 106(2), 253-262. https://doi.org/10.1111/j.00301299.2004.13057.x

75. Swemmer, A. M., Knapp, A. K., \& Smith, M. D. (2006). Growth responses of two dominant C 4 grass species to altered water availability. International Journal of Plant Sciences, 167(5), 1001-1010. https://doi.org/10.1086/505611

76. Tilman, D., \& Wedin, D. (1991). Plant traits and resource reduction for five grasses growing on a nitrogen gradient. Ecology, 72(2), 685-700. https://doi.org/10.2307/2937208

77. Tonnabel, J., David, P., \& Pannell, J. R. (2017). Sex-specific strategies of resource allocation in response to competition for light in a dioecious plant. Oecologia, 185(4), 675-686.

https://doi.org/10.1007/S00442-017-3966-5/TABLES/2

78. Towne, G. E., \& Kemp, K. E. (2003). Vegetation Dynamics from Annually Burning Tallgrass Prairie in Different Seasons. Journal of Range Management, 56(2), 185. https://doi.org/10.2307/4003903

79. USDA. (2021a). Conservation Plant Characteristics for Andropogon gerardii. http://plants.usda.gov/core/profile?symbol=ANGE

80. USDA. (2021b). Conservation Plant Characteristics: Sorghastrum nutans (L.) Nash.

81. Vinton, M. A., Hartnett, D. C., Finck, E. J., \& Briggs, J. M. (1993). Interactive effects of fire, bison (Bison bison) grazing and plant community composition in tallgrass prairie. American Midland Naturalist, 129(1), 10-18. https://doi.org/10.2307/2426430

82. Weaver, J. E., \& Fitzpatrick, T. J. (1932). Ecology and Relative Importance of the Dominants of TallGrass Ecology and Relative Importance of the Dominants of Tall-Grass Prairie Prairie. https://digitalcommons.unl.edu/agronomyfacpub/429

83. Weltzin, J. F., \& Coughenour, M. B. (1990). Savanna tree influence on understory vegetation and soil nutrients in northwestern Kenya. Journal of Vegetation Science, 1(3), 325-334. https://doi.org/10.2307/3235707

84. Wright, A. J., Mommer, L., Barry, K., \& van Ruijven, J. (2021). Stress gradients and biodiversity: monoculture vulnerability drives stronger biodiversity effects during drought years. Ecology, 102(1), e03193. https://doi.org/10.1002/ECY.3193

85. Wright, A., Schnitzer, S. A., \& Reich, P. B. (2014). Living close to your neighbors: the importance of both competition and facilitation in plant communities. Ecology, 95(8), 2213-2223. https://doi.org/10.1890/13-1855.1

\section{Figures}



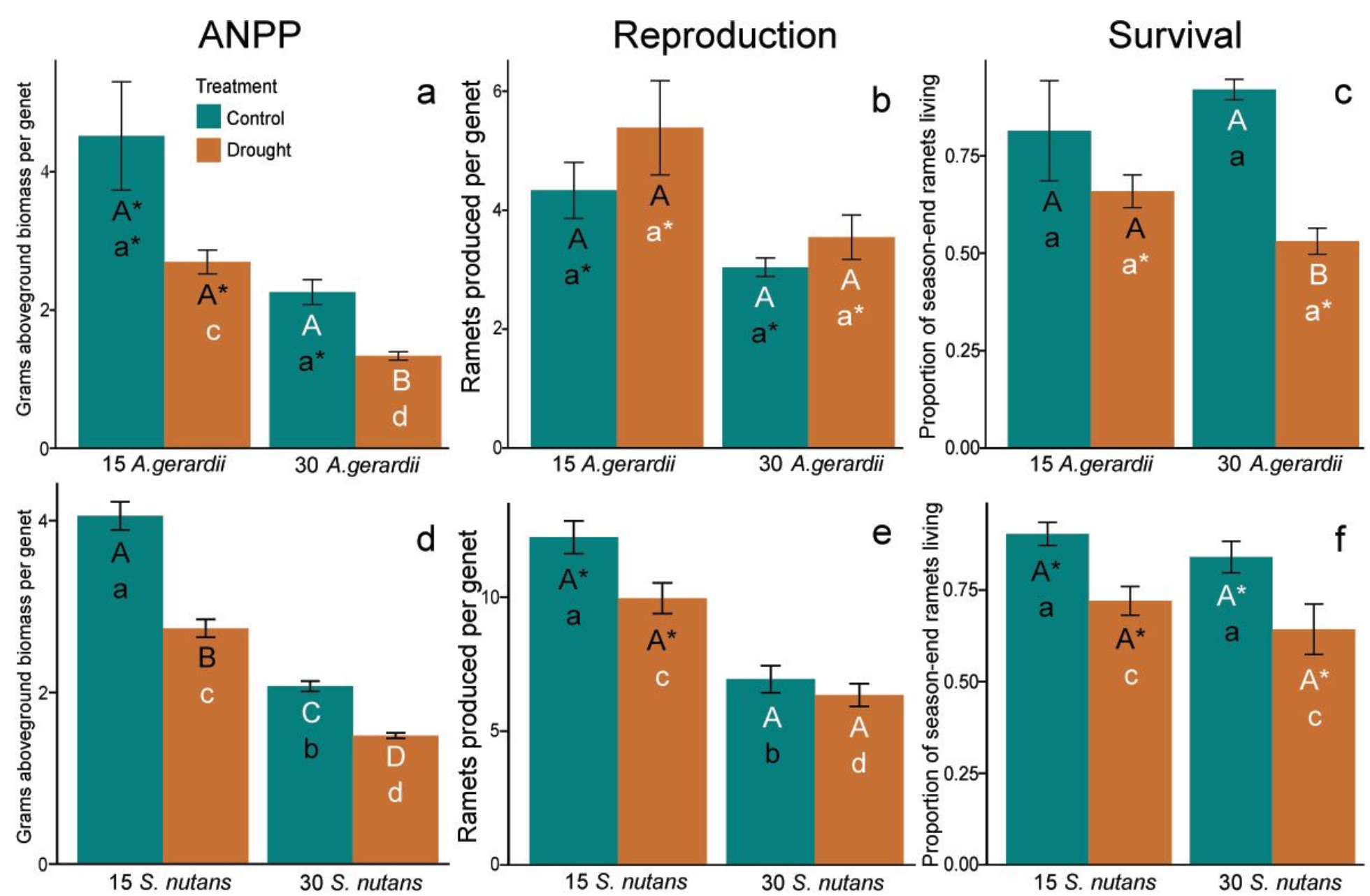

Figure 1

Performance of (a-c) A. gerardii and (d-f) S. nutans monocultures under late-season un-stressed (control) and stressed (drought) conditions at both low (15 genet) and high (30 genet) densities of identical competitor genets. Differing capital letters indicate significant differences resulting from the water treatment (at constant densities). Differing lower case letters indicate significant differences resulting from the density treatment within each water treatment. Asterisks indicate significant differences only prior to Bonferroni adjustment. Error bars indicate estimates of standard error.

ANPP

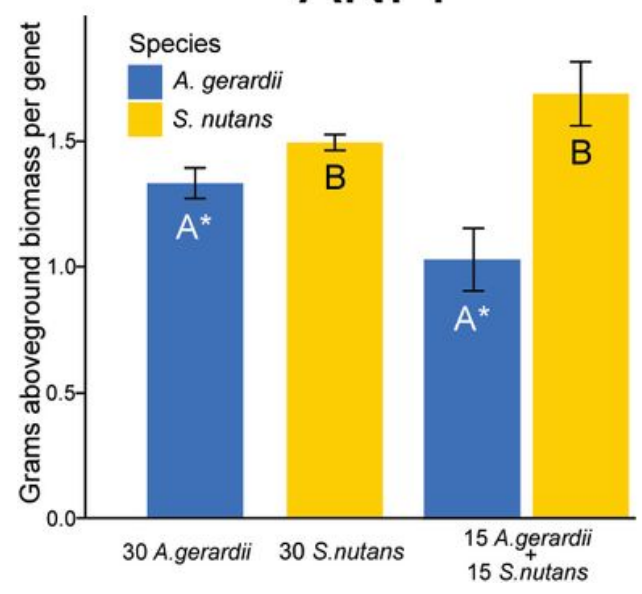

Reproduction

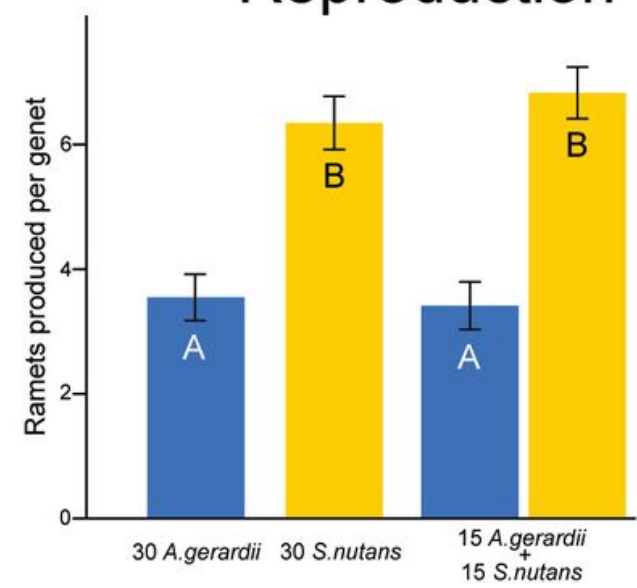

Survival

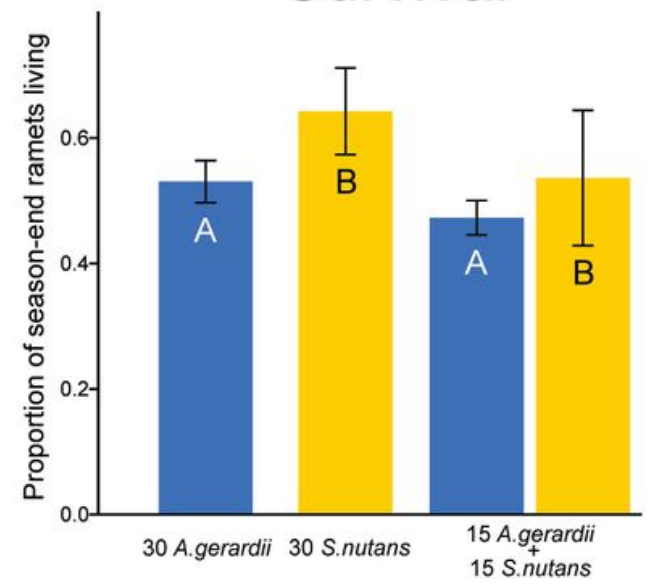


Figure 2

Performance of A. gerardii and S. nutans under the effect of interspecific competitors (right two columns). All communities depicted contained 30 total genets and were subjected to the late season drought treatment. Asterisk indicates significance only prior to adjustment $(0.008$

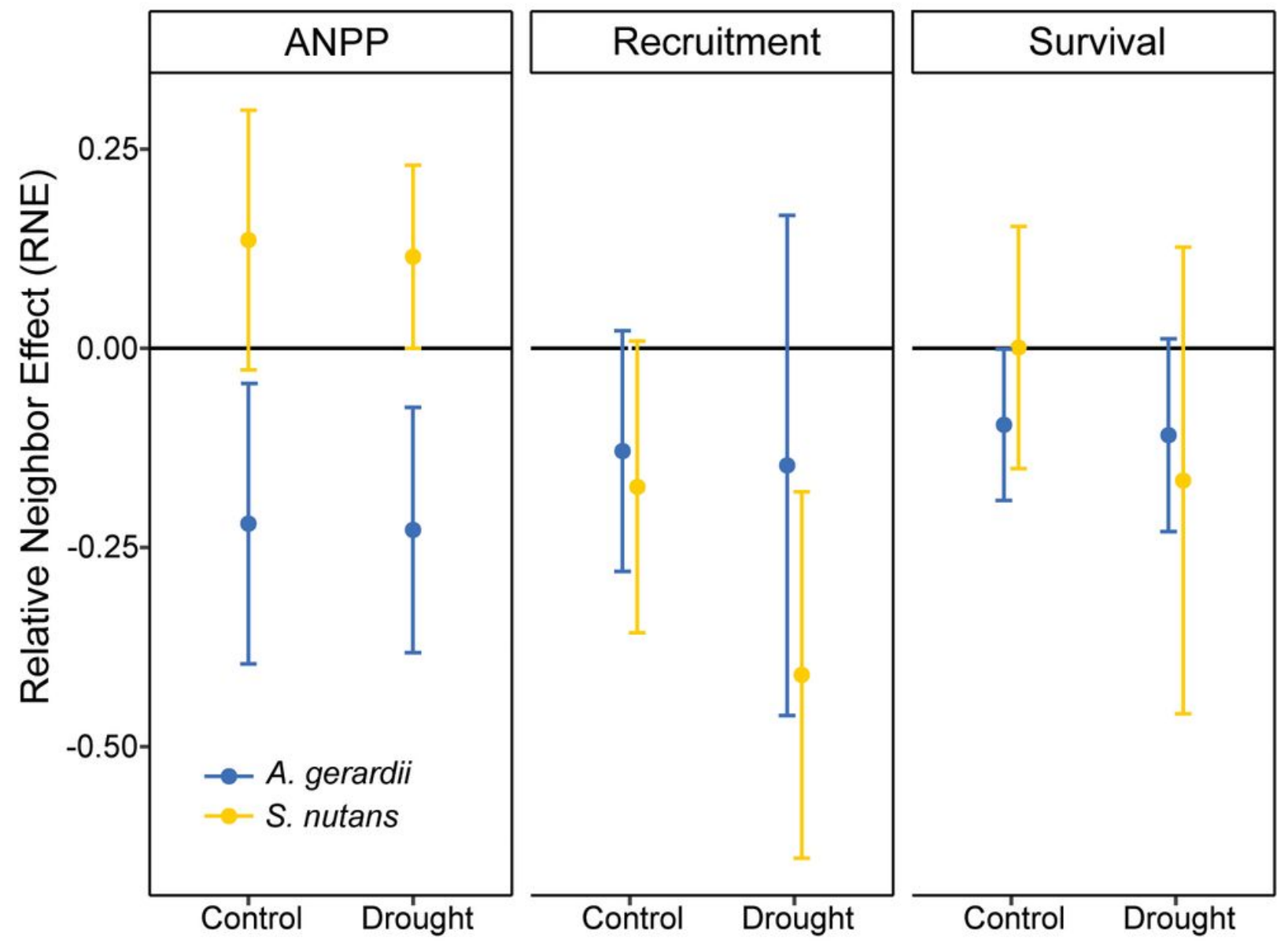

\section{Figure 3}

Relative neighbor effects of competing species A. gerardii and S. nutans. Values are averages for the five replicates within each watering and community treatment and error bars indicate $5 \%$ confidence intervals. Indicates the performance of the focal species in communities mixed with its competing species relative to its performance in monoculture at the same total community genet density. Performance metrics include, from left to right: ANPP (aboveground net primary production per genet), recruitment (ramets produced per genet), and survival (proportion of ramets produced that remained alive at experiment completion). Positive values indicate the focal species is facilitated by interspecific neighbors, negative indicates an antagonistic relationship, and a value of zero indicates that the performance of the focal species is unaffected by the species identity of its neighbor. 


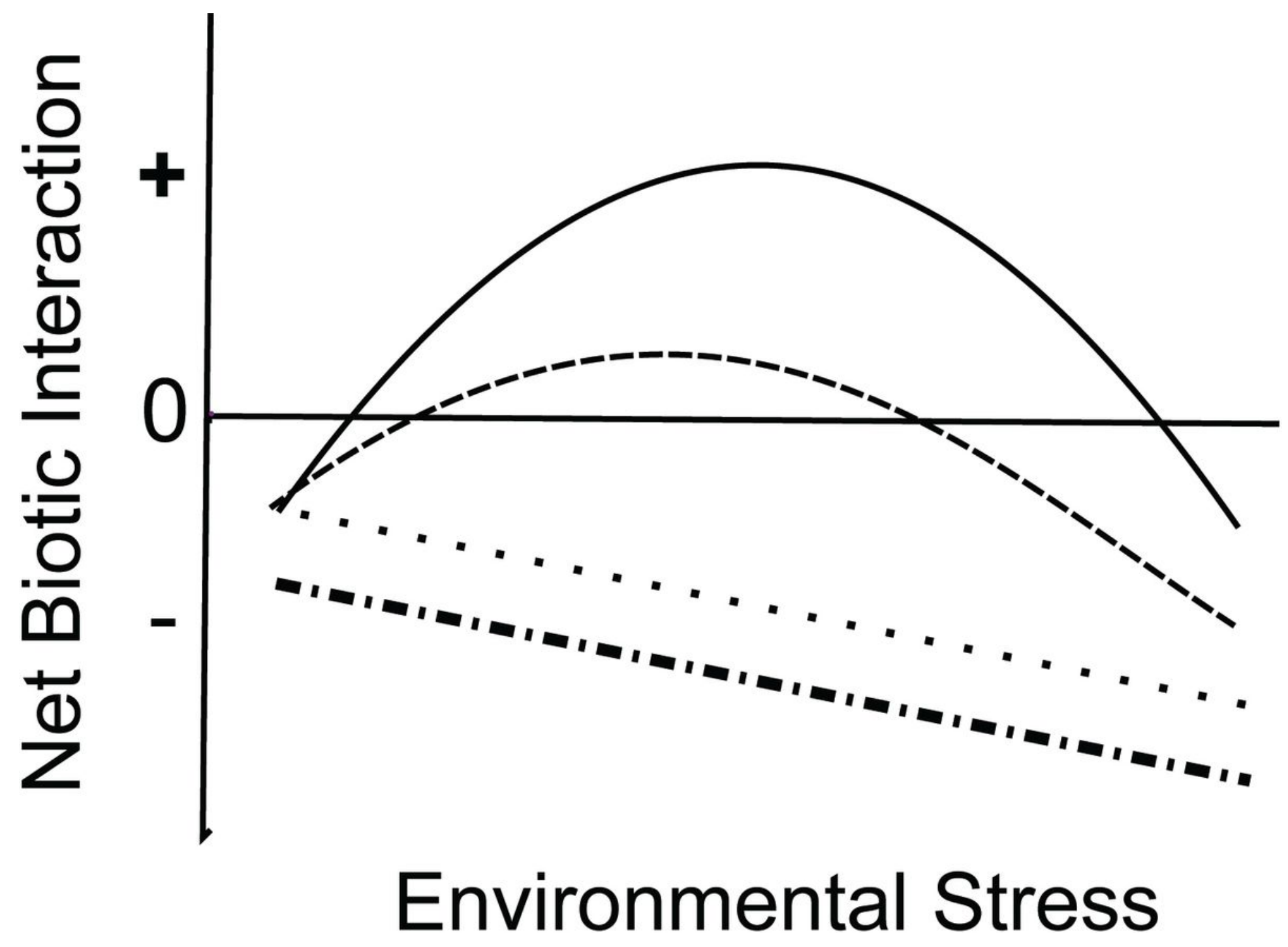

Figure 4

Proposed modifications to the framework for exploring the relationship between interspecific plant net biotic interactions and environmental stress. The existing framework is illustrated by the solid line, with the proposed modifications in the dashed and dotted lines. Interacting species resembling one another in the ways that they obtain resources and respond to stress and/or limitations in the availability of those resources may have fewer opportunities to shift net biotic interactions to positive when those stresses and resource limitations are encountered (dashed line). Species that perfectly resemble one another (dotted line) should see no benefit, nor detriment, from having interspecific rather than intraspecific neighbors under the stressful conditions. Increasing total density of identical competitors is expected to exacerbate negative interactions among them (dash-dot line) under the full range of environmental stress (ignoring density effects at very low densities, e.g., Allee effects).

\section{Supplementary Files}

This is a list of supplementary files associated with this preprint. Click to download. 
- SupplementaryFluxfacmds.docx

Page 21/21 